\title{
Analisis Peningkatan Struktur Ruas Jalan Tinggas Pamenggalan, Kecamatan Sendana, Kabupaten Majene, Provinsi Sulawesi Barat
}

\author{
Ahmad Yasin ${ }^{1}$ Milawaty Waris, . ST. MT ${ }^{2}$ dan Muhammad Harum ., ST. MT ${ }^{3}$ \\ Jurusan Teknik Sipil, Fakultas Teknik, Universitas Sulawesi Barat. \\ Jln. Prof. Dr. Baharuddin Lopa, SH, Talumung, Majene, Sulawesi Barat-Indonesia
}

\begin{abstract}
In general the road was built as a means to facilitate the mobility and accessibility of socio-economic activities in the community. The existence of roads is really needed to support the rate of economic growth, agriculture and other sectors. Considering the benefits that are so important, this is why the road construction and maintenance sector is very important. Road section Tinggas-Pamenggalan, Sendana District, Majene Regency, West Sulawesi Province. The method used in this study is data collection by interview or observation techniques (qualitative) in depth in the analysis of the structure of the elevation of the highways-pamenggalan sub-district of Sendana, Majene Regency, West Sulawesi Province. The are of the previous discussion, the researcher can draw conclusions. Based on the data taken at MC 0, the width of the road before work was only 2.5 meters and the average daily traffic conditions that passed were only motorbikes with the highest passing vehicles at $08.00-09.00 \mathrm{am}$ is 21 vehicles.

Preparation of the road body along the sta $0+000-2+337$ with a total volume of $11,868.00 \mathrm{~m} 2$.

From the concrete compressive strength test results above there are 4 samples with a concrete age of 14 days producing sample $\mathrm{A}=273.56$, sample $\mathrm{B}=289.32$, sample $\mathrm{C}=$ 301.32 and sample $\mathrm{C}=282.87$ then the quality of concrete exceeds the standard which has been determined, we can conclude that for concrete quality there are no problems.
\end{abstract}

Keywords: analysis of increased structure of the highways

\begin{abstract}
ABSTRAK
Secara umum jalan di bangun sebagai sarana untuk memudahkan mobilitas dan aksebilitas kegiatan sosial ekonomi dalam masyarakat. Keberadaan jalan sangatlah di perlukan untuk menunjang laju pertumbuhan ekonomi, pertanian serta sektor lainnya. Mengingat manfaatnya yang begitu penting maka dari itulah sektor pembangunan dan pemeliharaan jalan sangatlah penting. Ruas jalan Tinggas-Pamenggalan Kecamatan Sendana Kabupaten Majene Provinsi Sulawesi Barat. Metode yang di gunakan dalam penelitian ini adalah pengumpulan data dengan teknik wawancara atau observasi (kualitatif) secara mendalam pada analisis struktur peningkatan ruas jalan tinggaspamenggalan kecamatan sendana kabupaten majene provinsi sulawesi barat. Berdasarkan hasil dan pembahasan sebelumnya, peneliti dapat menarik kesimpulan Berdasarkan data yang di ambil pada MC 0 bahwa lebar jalan sebelum pekerjaan hanya 2,5 meter dan kondisi lalulintas harian rata-rata yang melintas hanya sepeda motor dengan kendaraan melintas paling tinggi yaitu pada pukul 08.00-09.00 adalah 21 kendaraan. Penyiapan badan jalan sepanjang sta $0+000-2+337$ dengan jumlah volume total $11.868,00 \mathrm{~m} 2$. Berdasarkan hasil uji tes kuat tekan beton diatas ada 4 sampel dengan dengan umur beton 14 hari menghasilkan sampel $A=273,56$, sampel $B=289,32$, sampel $C=301,32$ dan sampel $\mathrm{C}=282,87$ maka mutu beton melebihi standar yang telah di tentukan, maka dapat kami simpulkan bahwa untuk mutu beton tidak ada masalah.
\end{abstract}

Kata Kunci : Analisis Peningkatan Struktur Ruas Jalan 


\section{A. Pendahuluan}

\section{Latar belakang}

Kegiatan pekerjaan peningkatan struktur ruas jalan dengan perkerasan kaku (rigid pavement) dilaksanakan pada Ruas Jalan Tinggas-Pamenggalan yang terletak di Kecamatan sendana, Kabupaten majene.Kondisi exiting ruas jalan tinggas-pamengalan adalah konstruksi perkerasan kaku (rigid pavement).

Dalam hal peningkatan terhadap pelayanan transportasi masyarakat Pemerintah Kabupaten Majene melalui Dinas Pekerjaan Umum Bina Marga melakukan Perencanaan Peningkatan Struktur Ruas Jalan Tinggas-Pamenggalan Kecamatan Sendana Kabupaten Majene melakukan pembangunan jalan dengan menggunakan dana Anggaran Pendapatan dan Belanja Daerah Dana Alokasi Khusus Tahun Anggaran 2018. Karena kondisi jalan yang menuju desa Pamenggalan sangat rusak dan hanya kendaraan roda dua yang dapat melintas itupun dalam kondisi sangat di paksa karna faktor kebutuhan alat transportasi untuk melintas. Untuk meningkatkan ekonomi masyarakat maka pemerintah daerah melakukan pembangunan jalan ini melalui Anggaran Pembangunan Dan belanja Daerah, Dana Alokasi Khusus Tahun Anggaran 2018. Oleh karna itu judul yang diangkat adalah "Analisis Peningkatan Ruas Jalan Tinggas-Pamenggalan Kecamatan Sendana Kabupaten Majene Provinsi Sulawesi Barat".

2. Rumusan masalah

Penelitian ini berisi tentang Kegiatan Peningkatan Ruas Jalan Tinggas-Pamenggalan Kecamatan Sendana Kabupaten Majene, yang di kerjakan oleh PT.Bangun Sarana Nusantara. Maka acuan dalam penelitian ini adalah Selama kegiatan pekerjaan berlangsung penulis melakukan pengamatan dan pembelajaran terhadap proses pelaksanaan peningkatan ruas jalan Tinggas-Pamenggalan.

Adapun ruang lingkup penulisan dalam laporan tugas akhir ini terdiri dari :

a.Bagaimana Analisis Peningkatan Ruas Jalan Tinggas-Pamenggalan.

b. Bagaimana penyiapan Ruas badan Jalan dan mutu beton Tinggas-Pamenggalan.

3. Tujuan penelitian

Dengan berlandaskan pada judul tugas akhir, maka tujuan dari penulisan tugas akhir ini adalah merencanakan suatu kontruksi jalan dengan perkerasan kaku di atas timbunan badan jalan dari meterial yang dipilih dan mencukupi kebutuhan sesuai umur rencana.

a. Mengaplikasikan kinerja sebelum dan setelah peningkatan ruas jalan TinggasPamenggalan.

b. Menganalisis perencanaan penyiapan Ruas badan jalan dan mutu beton yang digunakan jalan Tinggas-Pamenggalan.

\section{B. Metode Penelitian}

1. Lokasi dan waktu penelitian

a. Lokasi penelitian

Lokasi penelitian ini dilaksanakan di ruas jalan Tinggas-Pamenggalan Kecamatan Sendana. Kabupaten Majene. Sulawesi Barat. Adapun lokasi dapat dilihat gambar di bawah: 


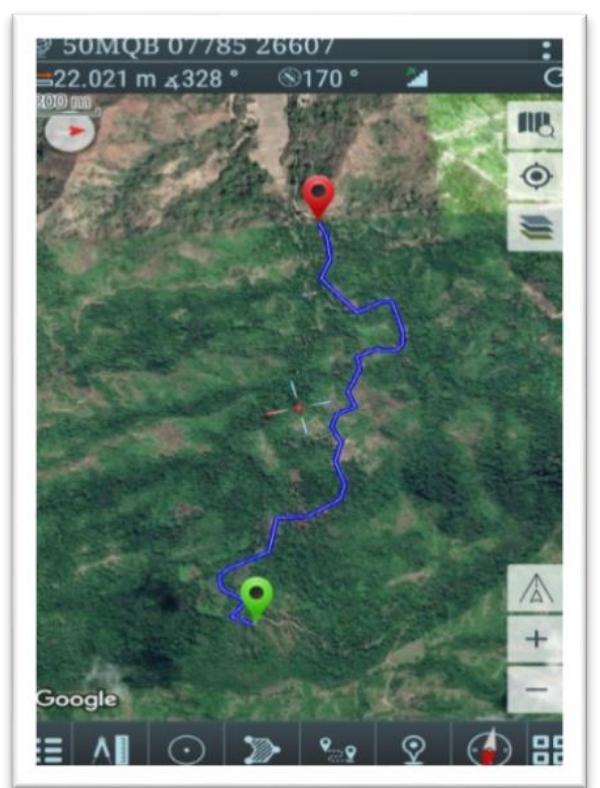

\section{Gambar 1 lokasi penelitian \\ Sumber : mgrs \& utm map \\ Skala: $\quad 1: 200$}

b. Waktu penelitian

Berdasarkan waktu penelitian ini dimulai pada bulan juli dimana dimulai penentuan lokasi penelitian selanjutnya pengumpulan literratur penunjang penelitian dan dilanjutkan pada proses analisis data penelitian selama kurang lebih 2 (dua) bulan, dimulai dari Bulan agustus sampai Bulan september.

2. Objek penelitian

Objek penelitian adalah Manajemen Proyek Peningkatan Struktur Ruas Jalan TinggasPamenggalan Kecamatan Sendana Kabupaten Majene Provinsi Sulawesi Barat.

3. Alat penelitian

Sesuai dengan apa yang di butuhkan agar mendapat hasil yang akurat maka di perlukan alat-alat sebagai berikut:
a. Alat tulis
b. Kamera
c. Meter ukur
d. Gambar pekerjaan
e. Dan lain-lain

4. Tindakan Penelitian

a. Pengumpulan Data Penelitian

Pengumpulan data dalam penelitian bersumber dari berbagai jurnal dan buku yang berhubungan dengan manajemen proyek. Sehingga penggunaan cara ini peneliti dapat mengetahui masalah tentang manajemen dalam proyek Peningkatan Ruas Jalan Tinggas-Pamenggalan Kecamatan Sendana Kabupaten Majene

b. Pengamatan Dilapangan

Pengamatan penelitian dilakukan langsung dilokasi penelitian untuk mengetahui dan mengerti bagaimana kondisi yang terjadi dilokasi penelitian serta melihat gambaran pekerjaan sehingga ketika peneliti mengalami kesulitan dilapangan dapat ditanyakan langsung pada pihak pengawas ataupun pelaksana dilapangan.

5. Data Penelitian

Data penelitian merupakan data masukan sebagai bahan analisis dalam penelitian ini. Data tersebut terdiri dari 2 (dua) macam yaitu:

a. Data Primer

Data primer merupakan data yang diperoleh dari hasil pengamatan langsung 
dilapangan.

b. Data Sekunder

Data sekunder merupakan data yang di peroleh dari instansi-instansi yang terkait.

6. Analisis penelitian

Analisis penelitian menggunakan metode (ASSTHO) American Assosiation Of State Highway And Transportation Officials kekuatan lentur beton, batang baja, jaring batang baja tulangan dan di fabrikasi untuk beton, dan batang dowel berlapis plastik jenis A

\section{Hasil dan Pembahasan}

1. Analisis Peningkatan Ruas Jalan

a. Evaluasi kerusakan jalan

Berdasarkan data skunder dari PT. Bangun Sarana Nusantara, kondisi jalan Tinggas-pamenggalan pada $\mathrm{MC} 0$ yang dilakukan sebelum pekerjaan menunjukan bahwa jalan Tinggas-Pamenggalan dari STA 0+000 - 2+337 mengalami rusak berat dan kondisi jalan yang sempit dengan kondisi exsisting jalan sebelum pekerjaan hanya 2,5 meter. Dan ada beberapa jalan yang terpotong karena tdak adanya jembatan atau plat dekker sehingga masyarakat sulit untuk melintas, ada beberapa titik yang di haruskan di bangun plat dekker atau jembatan Dapat dilihat pada tabel dibawah ini :

Tabel 1 kondisi kerusakan jalan yang membutuhkan plat dekker

\begin{tabular}{|c|c|l|}
\hline No & Stasiun & Keterangan \\
\hline 1 & $0+025$ & Plat dekker \\
\hline 2 & $1+100$ & Plat dekker \\
\hline 3 & $1+250$ & Plat dekker \\
\hline 4 & $1+500$ & Plat dekker \\
\hline 5 & $1+700$ & Plat dekker \\
\hline 6 & $2+100$ & Plat dekker \\
\hline
\end{tabular}

Sumber : Analisis data 2019

b. Analisa volume lalu lintas

Data volume lalu lintas jalan Tinggas-pamenggalan yang di dapat dari konsultan perencana sangat sedikit yang melintasi jalan ini dsebabkan medan yang mendaki dan terjal serta sempitnya badan jalan dan terkadang berlumpur saat hujan, disisi lain ada jalur lain yang bisa di lalui namun jaraknya dua kali lipat dari jalur ini. Dengan di bangunnya jalur ini di harapkan dapat memangkas waktu tempuh dan biaya yang di gunakan oleh masyarakat.

Klasifikasi untuk data lalu lintas Bisa di lihat pada tabel di bawah :

Tabel 2 Lintas Harian Rata-rata pada jalan tinggas-pamenggalan tahun 2018

\begin{tabular}{|c|c|c|c|c|}
\hline Waktu & $\begin{array}{c}\text { Kendaraan } \\
\text { berat } \\
(\mathrm{HV})\end{array}$ & $\begin{array}{c}\text { Kendaraan } \\
\text { ringan } \\
(\mathrm{LV})\end{array}$ & $\begin{array}{c}\text { Sepeda } \\
\text { motor } \\
(\mathrm{MC})\end{array}$ & Total \\
\hline $06.00-07.00$ & 0 & 0 & 15 & 15 \\
\hline $07.00-08.00$ & 0 & 0 & 7 & 7 \\
\hline $08.00-09.00$ & 0 & 0 & 21 & 21 \\
\hline $09.00-10.00$ & 0 & 0 & 8 & 8 \\
\hline $10.00-11.00$ & 0 & 0 & 5 & 5 \\
\hline $11.00-12.00$ & 0 & 0 & 9 & 9 \\
\hline
\end{tabular}




\begin{tabular}{|c|c|c|c|c|}
\hline $12.00-13.00$ & 0 & 0 & 4 & 4 \\
\hline $13.00-14.00$ & 0 & 0 & 7 & 7 \\
\hline $14.00-15.00$ & 0 & 0 & 5 & 5 \\
\hline $15.00-16.00$ & 0 & 0 & 12 & 12 \\
\hline $17.00-18.00$ & 0 & 0 & 17 & 17 \\
\hline
\end{tabular}

Sumber : Anilisis Data 2019

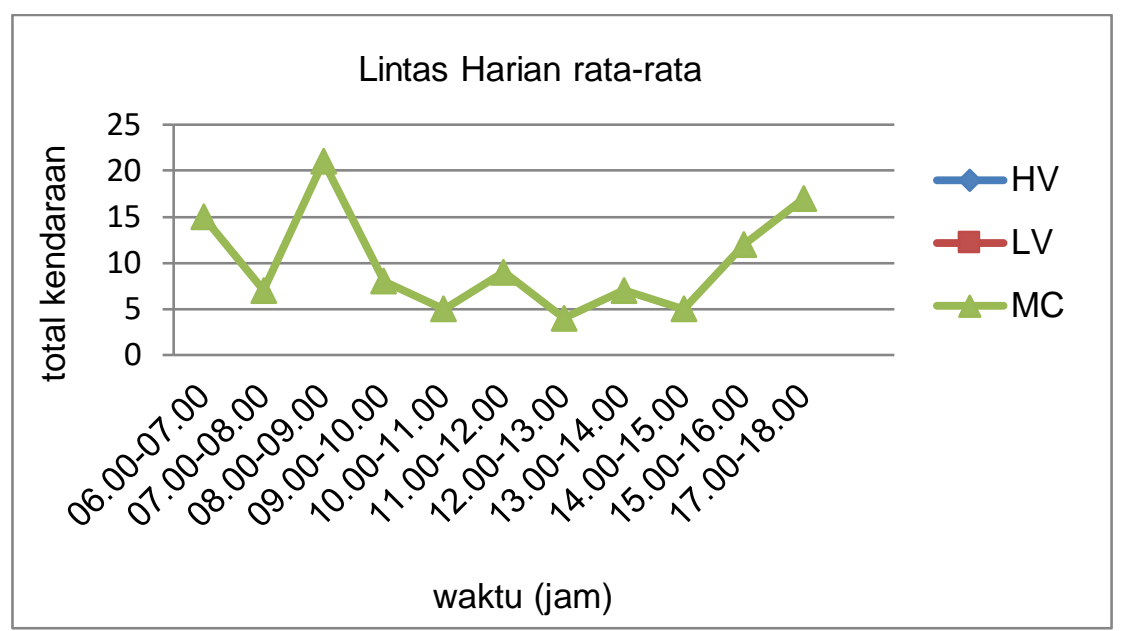

Gambar 2: grafik LHR pada jalan tinggas-pamenggalan tahun 2018

Sumber : Analisis Data 2019

Berdasarkan grafik di atas menunjukan puncak lalu lintas pada pukul $08.00-09.00$ yaitu 21 kendaraan bermotor yang melintas.

\section{Penyiapan Badan Jalan}

Pekerjaan ini mencakup penyiapan, penggaruan dan pemadatan permukaan tanah dasar atau permukaan jalan kerikil lama, untuk penghamparan Lapis Pondasi Agregat, Lapis Pondasi Jalan Tanpa Penutup Aspal, Lapis Pondasi Semen Tanah atau Lapis Pondasi Beraspal di daerah jalur lalu lintas (termasuk jalur tempat perhentian dan persimpangan) yang tidak ditetapkan sebagai Pekerjaan Pengembalian Kondisi. Untuk jalan kerikil, pekerjaan dapat juga mencakup perataan berat dengan motor grader untuk perbaikan bentuk dengan atau tanpa penggaruan dan tanpa penambahan bahan baru.

3. Rekapitulasi seluruh pekerjaan

Yang di maksud beton $\mathrm{K}$ adalah perhitungan kuat beton menggunakan perhitungan ( $\mathrm{Kg}$ / m2 ), dimana cara pengujiannya ialah menggunakan kubus beton dengan ukuran 15x15x15 cm. penerapan dari aturan PBI 1997 ( Peraturan Beton Bertulang Indonesia) yang menggunakan istilah untuk penyebutan kuat tekan beton K. Dan yang di maksud dengan beton $\mathrm{f}^{\prime} \mathrm{c}=20 \mathrm{mpa}$ perhitungan kuat beton menggunakan benda sampel silinder $15 \mathrm{~cm}$ x tinggi $30 \mathrm{~cm}$. Penerapan dari acuan peraturan baru SNI 03-2847-2002 yang menggunakan istilah untuk penyebutan kuat tekan beton dengan fc (mpa).

Untuk mengkonversi mutu beton $\mathrm{K}(\mathrm{Kg} / \mathrm{cm} 2)$ ke fc (mpa) pengujian mutu beton $\mathrm{K}$ menggunakan kubus $15 \times 15 \times 15$ yang memiliki konversi : 0,83 . Pada benda uji silinder dengan diameter $15 \mathrm{~cm}$ x tinggi $30 \mathrm{~cm}$ yang di gunakan pada mutu beton $\mathrm{fc}$ (mpa).

Contoh konversi beton K- 250 ke beton $\mathrm{fc}=20 \mathrm{mpa}$

$=250 \times 0,83$

$=207,5 \mathrm{~kg} / \mathrm{cm} 2$ konveversi $=20 \mathrm{mpa}$ 
Jadi beton $\mathrm{K}-250$ dan beton $\mathrm{fc}=20 \mathrm{mpa}$ sama.

Dari penjumlahan seluruh peekerjaan dapat dilihat pada tabel di bawah ini :

Tabel 3 Rekapitulasi Seluruh Pekerjaan

\begin{tabular}{|l|l|l|l|l|l|}
\hline No & Jenis Pekerjaan & Volume & $\begin{array}{l}\text { Durasi } \\
\text { Waktu }\end{array}$ & Mutu & Ket \\
\hline 1 & $\begin{array}{l}\text { Galian Untuk Selokan } \\
\text { Drainase \& Saluran Air }\end{array}$ & $591,50 \mathrm{~m} 3$ & 3 Minggu & - & - \\
\hline 2 & $\begin{array}{l}\text { Galian Pasangan Batu } \\
\text { Mortar }\end{array}$ & $293,67 \mathrm{~m} 3$ & 7 Minggu & - & - \\
\hline 3 & Galian Biasa & $1.339,17 \mathrm{~m} 3$ & $2 \mathrm{Minggu}$ & - & - \\
\hline 4 & Timbunan Pilihan & $1.717,74 \mathrm{~m} 3$ & $3 \mathrm{Minggu}$ & Kelas c & - \\
\hline 5 & Penyiapan Badan Jalan & $11.868,00 \mathrm{~m} 2$ & $5 \mathrm{Minggu}$ & - & - \\
\hline 6 & $\begin{array}{l}\text { Perkerasan Beton Semen } \\
\text { K-250 }\end{array}$ & $2.126,00 \mathrm{~m} 3$ & $19 \mathrm{Minggu}$ & F'c=20 Mpa & - \\
\hline 7 & Beton Plat Dekker & $12,88 \mathrm{~m} 3$ & $3 \mathrm{Minggu}$ & F'c=20 Mpa & - \\
\hline 8 & Baja Tulangan U 24 Polos & $1.368,37 \mathrm{Kg}$ & $3 \mathrm{Minggu}$ & $\mathrm{kN} / \mathrm{cm} 2$ & - \\
\hline
\end{tabular}

Sumber : Analisis Data 2019

Pengujian hasil tes kuat tekan beton di laboratorium dapat dilihat pada tabel berikut:

Tabel 4 Hasil Tes Kuat Tekan Beton

\begin{tabular}{|c|c|c|c|}
\hline No & Sampel & $\begin{array}{c}\text { Umur } \\
\text { (Hari) }\end{array}$ & $\begin{array}{c}\text { Tegangan } \\
(\mathrm{Kg} / \mathrm{Cm} 2)\end{array}$ \\
\hline 1 & $\mathrm{~A}$ & 14 & 273,56 \\
\hline 2 & $\mathrm{~B}$ & 14 & 289,32 \\
\hline 3 & $\mathrm{C}$ & 14 & 301,23 \\
\hline 4 & $\mathrm{D}$ & 14 & 282,87 \\
\hline
\end{tabular}

Sumber : Analisis Data 2019

Dari hasil tabel tes kuat tekan beton diatas ada 4 sampel dengan dengan umur beton 14 hari menghasilkan sampel $A=273,56$, sampel $B=289,32$, sampel $C=301,32$ dan sampel $\mathrm{C}=282,87$ maka mutu beton melebihi standar yang telah di tentukan, maka dapat kami simpulkan bahwa untuk mutu beton tidak ada masalah.

\section{D.Penutup}

1. Kesimpulan

dari hasil dan pembahasan sebelumnya, peneliti dapat menarik kesimpulan Berdasarkan data yang di ambil pada MC 0 bahwa lebar jalan sebelum pekerjaan hanya 2,5 meter dan kondisi lalulintas harian rata-rata yang melintas hanya sepeda motor dengan kendaraan melintas paling tinggi yaitu pada pukul 08.00-09.00 adalah 21 kendaraan.

Penyiapan badan jalan sangatlah penting untuk pembangunan jalan karena hal ini yang akan menentukan kuat umur jalan. Pekerjaan penyiapan badan jalan di kerjakan dari stasiun $0+000-2+337$ dengan volume $11.868,00 \mathrm{~m}^{2}$ dengan durasi waktu selama 5 minggu, Dan memakai timbunan pilihan $1.717,74 \mathrm{~m}^{3}$ dengan durasi waktu pekerjaan selama 3 minggu, pekerjaan perkerasan beton K-250 atau beton mutu sedang f'c $=20 \mathrm{Mpa}$ dengan volume $2.126,00 \mathrm{~m}^{3}$ dengan durasi waktu selama 19 minggu.

Dari hasil tabel tes kuat tekan beton ada 4 sampel dengan dengan umur beton 14 hari menghasilkan sampel $A=273,56$, sampel $B=289,32$, sampel $C=301,32$ dan sampel $\mathrm{C}=282,87$ maka mutu beton melebihi standar yang telah di tentukan, maka dapat kami simpulkan bahwa untuk mutu beton tidak ada masalah. 
2. Saran

Disarankan kepada pihak pelaksana/kontraktor agar dapat menggunakan managemen proyek lebih maksimal lagi untuk menghindari keterlambatan waktu yang bisa mengakibatkan proyek lambat untuk di selesaikan. Kepada pihak konsultan perencana agar lebih detail dalam perencanaannya, seperti kondisi geoteknik dan geometrik jalan.

penulis yakin bahwa penelitian ini masih mempunyai banyak kekurangan maka di sarankan agar hasil penelitian ini di lakukan penelitian kembali yang lebih spesifik dan mendetail demi kesempurnaan penelitan ini.

Penelitian selanjutnya harus disertai kerja sama dengan pemerintah agar bisa di tindak lanjuti dan dapat di selesaikan jika ada permasalahan pada objek penelitian.

\section{E. Daftar Pustaka}

AASSTHO, (American Assosiation Of State Highway And Transportation Officials) kekuatan lentur beton, batang baja, jaring batang baja tulangan dan di fabrikasi untuk beton, dan batang dowel berlapis plastik jenis A.

Abstraksi, (1999) undang-undang no 18 tahun 1999 tentang jasa konstruksi.

Anugrah dan arrowy,(2014) melakukan tentang "perncanaan lapis tambahan (overlay) dan rencana anggaran biaya pada ruas jalan ponorogo-menang (Sta 202+600 -208+000) kabupaten ponorogo"

Ari Suryawan (2009) buku perkerasan jalan beton semen portland,perencanaan metode ASSHTO 1993 spesifikasi, parameter desain dan contoh pergitungan cetakan ke 42015

Ari Syahrudin. S (2010) melakukan penelitian mengenai "pengujian daya dukung perkerasan jalan dengan DCP sebagai standar untuk perkerasan jalan"

Effendi, (2015) melakukan penelitian mengenai "Analisis Perhitungan tebal lapis tambahan pada jalan pangeran suryanata-patung lembuswana kota samarinda"

Kementrian pekerjaan umum dan perumahan rakyat badan pengembangan sumber daya manusia pusat pendidikan dan pelatihan jalan, perumahan permukiman, dan pengembangan infrastruktur wilayah, (2016) modul 5 spesifikasi pelebaran perkerasan dan bahu jalan.

Leo Santosa (2010) meneliti tentang analisis dampak beban overloading kendaraan pada struktur rigid pavement terhadap umur rencana (studi kasus ruas jalan simp lago-sorek $\mathrm{Km} 77 \mathrm{~s} / \mathrm{d} 78)$.

MKJI, (1997) manual kapasitas jalan indonesia perkerasan kaku(rigid pavement)

Nirwana Puspitasari (2016), melakukan penelitian mengenai "pengaruh penigkatan ruas jalan terhadap perubahan kapasitas jalan dan lingkungan"

Silvia sukirman (1999) buku dasar-dasar perencanaan geometrik jalan 